\title{
Geochemical and mineralogical characterization of coastal sediments in Al-Hoceima Bay (Central Rif, Morocco)
}

\author{
Mustapha Lamgharbaj ${ }^{1,}{ }^{*}$, Rachid El Ansari ${ }^{1}$, Hajar El Talibi ${ }^{1}$, Said El Moussaoui ${ }^{1}$, Hinde Cherkaoui Dekkaki $^{1}$, and Issam Etebaai $^{1}$ \\ ${ }^{1}$ Laboratory of Research and Development in Engineering Sciences, Faculty of Science and Technology of Al Hoceima, Abdelmalek \\ Essaadi University, Tetouan, Morocco
}

\begin{abstract}
This work aims to characterize the morphosedimentaty dynamics of the shores of Al-Hoceima Bay through geochemical and mineralogical analysis of surface sediments. The results reveal a direct relationship between marine hydrodynamic forcing on the one hand and detrital inputs from land on the other. Calcimetric analysis makes it possible to highlight the transport and deposition processes at the beaches of Al-Hoceima bay. The difference in the reasonably high carbonate contents in the western beaches (Isli, Cala Bonita and Quemado) (> 60\%) and low in the beaches of the central and eastern zone (Sfiha, Souani, Salina and Lharch $)(\approx 15 \%)$ are mainly due to the influence of coastal currents, littoral drift, and fluvial action. The higher levels of heavy minerals in Lharch beach (18\%) are expressed by volcanic outcrops of Cap Quelates and Jbel Tamsamen. The low values at the Souani and Tayth beaches (7\% on average) are due to erosion by the two types of coastal drift, NW-SE and NNE-SSW, which carry the sediments of schist origin brought by the Oueds Ghiss and Nekôr. In contrast, the reasonably high contents in the Sfiha beach (12\%) are attributed to the accumulation of allochthonous sediments by NW-SE littoral drift which carries sediments of volcanometamorphic origin from Rass Quelates.
\end{abstract}

\section{Introduction}

Soft or sandy Shorelines are fragile and vulnerable spaces where human pressure. Morocco coastal Mediterranean area is the subject of numerous particle size and mineralogical studies of surface sediments, mainly [1], [2], [3], [4], on the bay of Tangier, [5], on Al-Hoceima Bay, and [6], [7], for the Bay of Said. The morphology of the beaches is linked to the source of the sediments that feed them and the energy involved in the transport and deposition of sediments on the coastal fringe. Mineralogical and geochemical analysis of beach sediment identifies the relationship between transport, sedimentation, and sediment condition. The coastal area, especially the beaches of the Ghiss-Nekôr plain and Al Hoceima, have inspired man's action. They have undergone a wide range of facilities and activities, including port facilities, several tourist sites, waterworks on rivers (Abd Elkhatabi Dam on Oued Nekôr) etc. As a result, coastal operations are disrupted by these developments [6]. A superficial collection of 33 sand samples was carried out in different parts of the beaches of Al Hoceima Bay on both sides of the oueds, along 17 profiles perpendicular to the shoreline whose objective is to characterize the morpho-sedimentary sediment from the shores of this bay through geochemical and mineralogical analysis of the superficial sediments.

\footnotetext{
* Corresponding author: lamgharbaj123mustapha@gmail.com
}

\section{Study site}

The Bay of Al Hoceima is located in the North of Morocco (Central Rif) on the southern facade of the Mediterranean, especially to the East of the city of $\mathrm{Al}$ Hoceima (Fig. 1). The bay is open to the North in an arch delimited by two rock formations: Ras Terf (Cap Quelates) to the East and Rass El Abed (Cap Maure) to the west. This bay extends over $40 \mathrm{~km}$ of coastline with more than $15 \mathrm{~km}$ of beaches. It is between $35^{\circ} \mathrm{W} 14^{\prime}$ and $35^{\circ} \mathrm{W} 12^{\prime}$ longitude and between $3^{\circ} \mathrm{N} 55^{\prime}$ and $3^{\circ} \mathrm{N} 46^{\prime}$ latitude. It is bounded to the North by the southern part of the Alboran Sea and south by the Ghiss-Nekôr plain (city of Imzouren) (Fig. 1). Al Hoceima Bay is considered one of the largest bays in the Mediterranean. It has quite remarkable ecological and tourist potential. The hydrodynamics in this bay depends on the general dynamics of the Mediterranean. The marine zone of $\mathrm{Al}$ Hoceima is characterized by the anticyclonic gyre, which is oriented East-West [8]. The most frequent swells in the study area originate from WNW [8]. Those in the NE to ENE area are primarily to be considered. The NE swells cause coastal transit to the west of this bay. The GhissNekôr plain is made up of fillings of the heterogeneous alluvial quaternary (sand, gravel, and conglomerates) ranging from the Pliocene to the present [9], [10]. The study area is characterized by an alternation of several different morphological units from one sector to another. 
Rocky cliffed coasts are found in Capes, sandy coasts in the central part, and two largemouths (Ghiss, Nekôr).

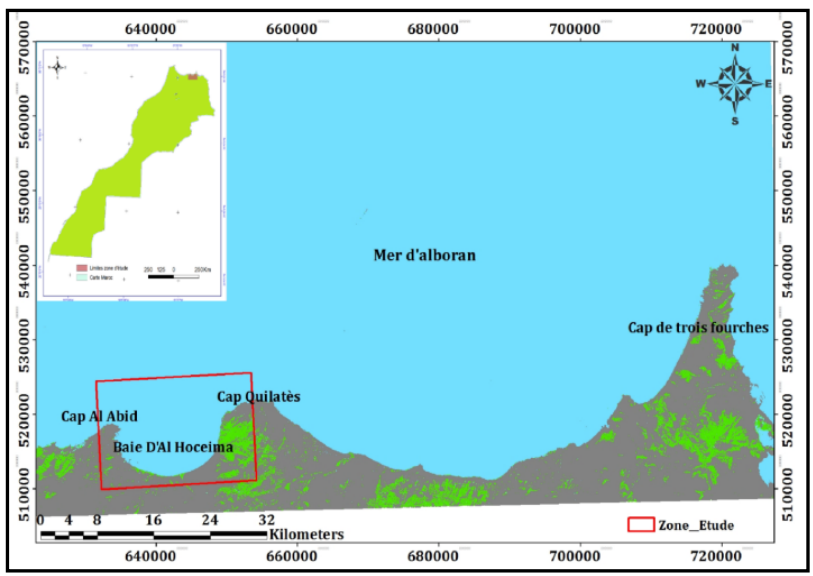

Fig. 1. Location of Al-Hoceima bay.

\section{Materials and methods}

\subsection{Sand sampling}

Thirty-three surface sand samples were collected using buckets during November and December 2019 and January 2020 and stored in transparent and airtight plastic bags. These sampling points are broken down into 17 profiles themselves into four sectors (Fig. 2). The processing and experimental sample operations were carried out at the laboratory of the Faculty of Science and Technology of Al Hoceima.

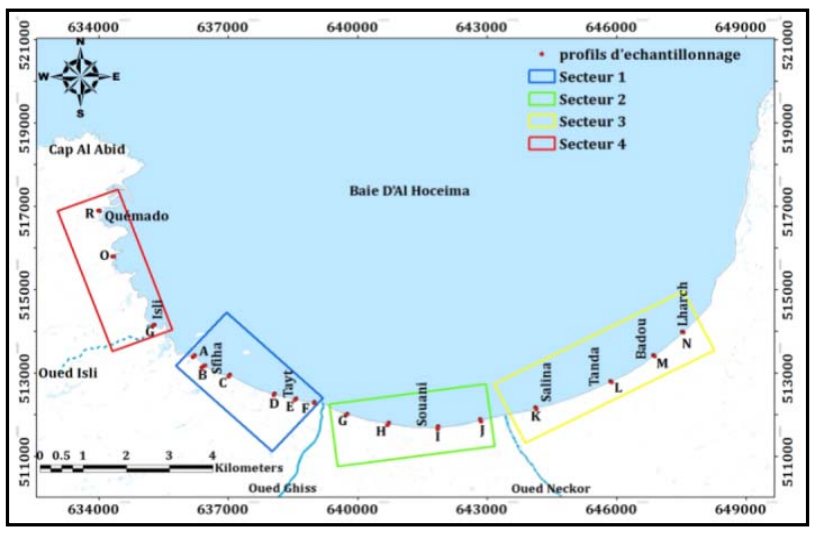

Fig. 2. Sector-based sediment sampling patterns at Al Hoceima Bay beaches.

\subsection{Calcimetric analysis}

We used the calcimetry method: the sand sediment in the mesh is less than $2 \mathrm{~mm}$ is ground and then dried. $0.1 \mathrm{~g}$ of this crushed sediment, which is cold and hot-pressed with hydrochloric acid ( $\mathrm{HCl})$ above a stirrer, is taken. Excess acid is titrated by sodium hydrolysis $(\mathrm{NaOH})$. This study measures the volume of carbon dioxide $\left(\mathrm{CO}_{2}\right)$ released by a sediment sample. This analysis makes it possible to know the amount of calcite present in the sediment. The calculation of the percentage of $\mathrm{CaCO} 3$ is based on a control test of pure calcite. The following formula obtains the percentage of carbonates:

$\% \mathrm{CaCO} 3=\frac{(V e 2-V e 1)}{(V c 2-V c 1)} \times 100$

Vc2-vc1 is derived from the pure calcite (control) reading, and $\mathrm{Ve} 2-\mathrm{Ve} 1 \mathrm{e}$ is the volume of $\mathrm{CO} 2$ from the sand sample released in the reaction.

\subsection{Heavy minerals analysis}

The mineralogical study method is carried out according to the experimental protocol proposed by Parffenoff et al. (1970). This technique consists of several steps and which are respectively:

- Preparation of samples,

- The separation of minerals,

- Assembly of minerals,

According to their density, the minerals constituting the sands are conventionally divided into two main groups: Heavy minerals with a density greater than 2,89 (Zircon, Amphibole, Olivine, and tourmaline, etc.) and light minerals with a density of less than 2.89 (quartz and feldspar). The preparation of the scales was carried out following a series of treatments (Wet sieving of the sediments under a net of ordinary water by a sieve of mesh $400 \mu \mathrm{m}$ embossed in a sieve of $50 \mu \mathrm{m}$, the sands are decalcified by $\mathrm{HCl}$ cold then hot and Drying in the oven for 24 hours under a temperature of $105^{\circ} \mathrm{C}$ ). Density separation was performed using 2.89 -density bromoform $(\mathrm{CHBr} 3)$ as a separator [11]. Heavy mineral blades were mounted between blades and slats using Canadian balm (two blades for each sample) on a hot plate to soften the viscous material after a series of treatments (sands are decalcified by $\mathrm{HCl}$ cold then hot).

\section{Results and discussion}

\subsection{Contents of carbonates}

Carbonate levels in the coasts of Al Hoceima Bay vary widely from the beach to beach and range from 9 to $70 \%$ (Fig. 3; 4). Carbonate levels in Sfiha range from 9.2\% to $15.4 \%$ and are marked by a slight increase from west to East. The same trend is recorded at the Tayth beach, increasing from 13 to $14.50 \%$ eastward. From the right bank of the Nekôr mouth to the East of the Lharch beach, carbonate levels gradually increase by about 16 to $26 \%$. The three beaches Quemado, Cala Bonita, and Isli, have the highest carbonate content $(60 \%$ to $70 \%)$. The transverse evolution decreases the carbonates from the top to the bottom estran (Fig. 3; 4).

The level of $\mathrm{CaCO}_{3}$ present in the sand samples tells us about the levels of calcite of geological and biogenic origin. Based on the longitudinal and transverse evolution analysis along the beaches of Al Hoceima bay, we found a direct relationship between marine hydrodynamic forcings on the one hand and detrital inputs on the other. 


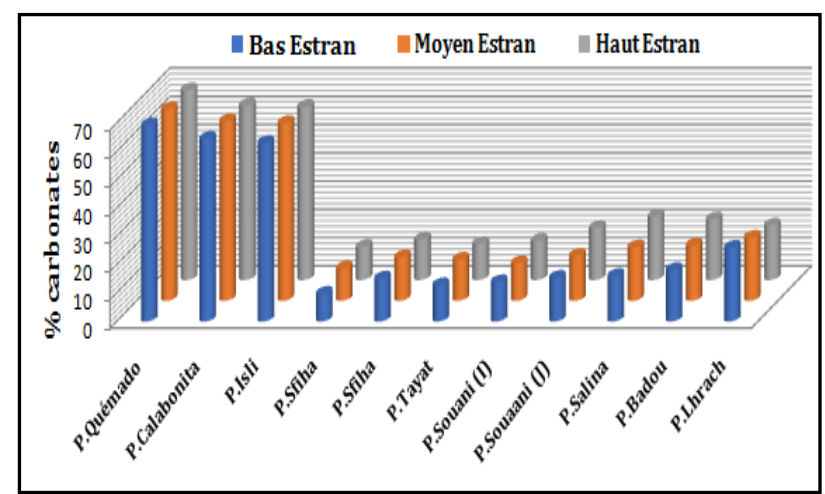

Fig. 3. Carbonate content of sand at the beaches of $\mathrm{Al}$ Hoceima Bay.

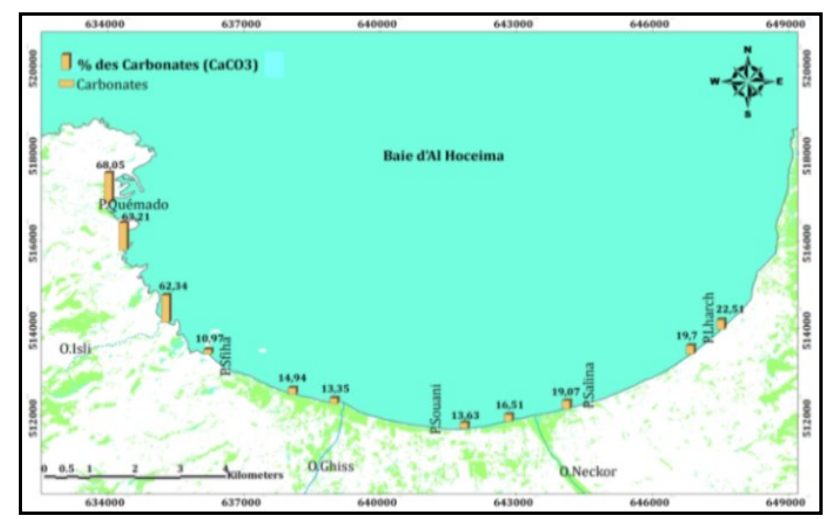

Fig. 4. Average Distribution of Sand Carbonate Levels at AlHoceima Bay Beaches.

In general, the results of calcimetry make it possible to highlight the transport and sedimentation processes at the bay beaches. Indeed, the difference in carbonate levels between the West beaches (Isli, Cala Bonita, and Quemado) and the central area of the bay (from Sfiha beach to Lharch) is mainly due to the influence of coastal currents, coastal drift, and fluvial action.

Carbonate inputs are of low biogenic origin (shells) and mainly detritic due to wave agitation on calcareous cliffs. This allows us to conclude that sand sediments in this area are generally Aboriginal due to local erosion of the cliffs and drainage of the hinterland that provides a high percentage of carbonates $>$ to $65 \%$. The low percentages thus are due to two main factors; the first is the marine erosion of the cliffs of Rass Tarf, which are volcanic origin formations devoid of calcite. The coastal drift of the NW-SE swell moves eroded particles to form the sediments of its beaches. The second is the river action of the Ghiss and Nekôr.

\subsection{Heavy mineral contents}

The sands' heavy mineral contents range from $6 \%$ to $18 \%$ at beaches in Al Hoceima Bay (Fig. 5). The high proportions were noted at the Lharch beach with $18 \%$, followed by the Sfiha beach with $12 \%$ and then Quemado with $10 \%$. The lowest levels were found at the mouth of Oued Ghiss (east of Tayth beach) and Souani beach with $8 \%$ and $6 \%$, respectively (Fig. 5).

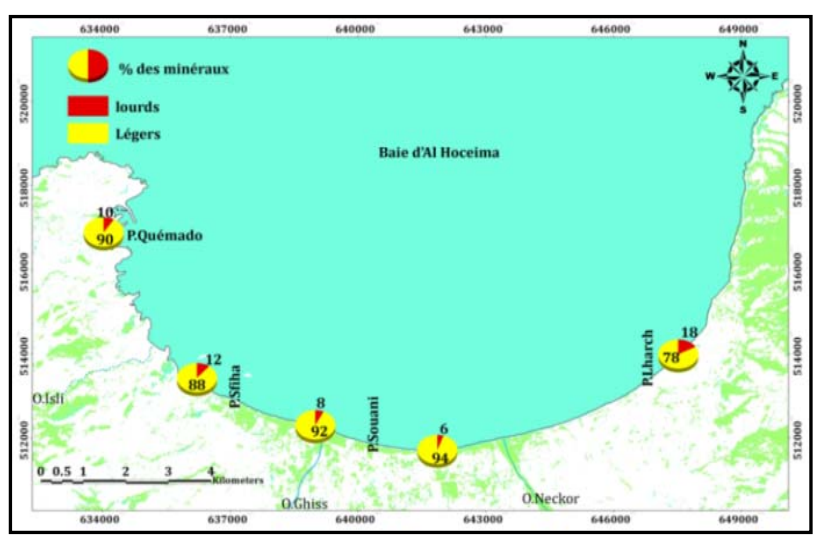

Fig. 5. Percentage of heavy and light minerals in sandy sediments at the beaches of Al Hoceima Bay.

The mineralogical analysis was carried out on five samples of the sandy fraction at different bay beaches. The higher quantity in Lharch beach is expressed by volcanic outcrops in Cape Quelates and Jbel Tamsamen on the one hand and may come from eroded sediments at the Nekôr mouth on the other. At the Souani and Tayth beaches, the low values in heavy minerals are due to erosion by the two types of coastal drift, NW-SE and NNE-SSW, which load sediments of shale origin brought by the Ghiss and Nekôr Oueds. Relatively high heavy mineral contents in Sfiha Beach (12\%) with the presence of olivine in some beaches (Lharch and Sfiha) are attributed to the accumulation of allochthone sediments of blackish hue by NW-SE, which supports the sediments of metamorphic volcano origin of Rass Quelates.

\section{Conclusion}

As a result of this work, we were able to characterize the dynamics of surface sediments along the shores of AlHoceima bay. The amount of heavy minerals varies along the shoreline of Al-Hoceima Bay. It is marked by the high value $(18 \%)$ in the Lharch range. This is due to the presence of volcanic outcrops in Cape Quelates. Calcimetry showed that the carbonate levels in the sediments studied are variable at this shoreline; the lower values are found in the central part of this bay $(6 \%)$. This is due to the dominance of shale geological formations in the Ghiss and Nekôr catchment innervated in this coastline's diet.

\section{References}

1. A. Boughaba, Thèse de Doctorat, Fac. Lettres, Nantes, (1992)

2. A. El Arrim, Thèse de Doctorat, Université. Abdelmalek Essaadi, Fac. Sci. Tech. Tanger, (2001)

3. I. El Hatimi, M.Achab, B. El Moumni, Bull. Inst. Sci., 24, 49-58, (2002)

4. M.Achab, B. El Moumni, A. El Arrim, J.M. Gutierrez Mas, Bull. Inst. Sci, (27), 00-00, (2005)

5. B. Gensous, M. Tesson, Mines, Géol. et Energie., 46, 127-134, (1979) 
6. M. Bouabdallah, Thèse de doctorat. Paris Est, (2008)

7. N. Bellahbib, H. Rezqi, M. Oujidi, S.Bengamra, LARHYSS Journal, (24), 19-40, (2015)

8. A. Khouakhi, Thèse de doctorat, université Mohamed, (2013)

9. A. Salhi, Thèse de doctorat, Université Abdelmalek Essaadi, Faculté Sciences, (2008)

10. N. Iouzzi, Mémoire DESS, Université Med V, (2008)

11. A. Parfenoff, C. Pomerol, J. Tourenq, Sédim Pétrol, Vol 34(4), 830-847, (1970) 